\title{
BIOMECHANICAL STUDY OF VARIOUS SURGICAL FIXATION METHODS AS TESTED ON CADAVEROUS HUMAN LUMBAR SPINE SAMPLES
}

\author{
Jiří Charamza*a , Lumír Hrabálek ${ }^{\mathrm{b}}$, Jiří Keprtc ${ }^{\mathfrak{c}}$ Luděk Bartoněk ${ }^{\mathrm{d}}$
}

\author{
a Department of Anatomy, Medical Faculty, Palacký University, 77515 Olomouc, Czech Republic \\ Department of Neurosurgery, University Hospital, 77520 Olomouc, Czech Republic \\ Joint Laboratory of Optics of Palacký University and Physics Institute of Czech Academy of Sciences, 77200 \\ Olomouc, Czech Republic \\ d Department of Experimental Physics, Natural Science Faculty, Palacký University, 77200 Olomouc, \\ Czech Republic
}

Received July 20, 2000

Key words: Lumbar spine / Interbody fusion / Translaminar fixation / Interbody fusion

The goal of this work is to evaluate the degree of stability of various surgical fixation methods by biomechanical analysis of the human lumbar spine. This measuring was carried out on cadaverous samples of the lumbar spine using precisely defined mechanical loads on the spinal samples, including pressure, flexibility, torsion and combinations thereof and was done prior to the development and manufacture of original mechanical electrical equipment for the measurement of deformed samples of the spine. A part of this work is the observation of deformation and a presentation of the results of the measurement of various methods of stabilization of the spine. The acquired information leads to an optimalization of surgical operations on the lumbar spine.

\section{INTRODUCTION}

Starting in the so-called third age of each human being, degenerative changes start to take place in every part of the spine and especially in the lower part of the backbone. The degree and speed of the progress of these changes is individual and clinically noticeable at some point in the course of life of up to 80 percent of the population. Degeneration of the spine takes place in three stages ${ }^{13}$ :

1. The dysfunction stage is characterized by degeneration of the nucleus pulposus with laceration of the anulus fibrosus of the lower intervertebral discs and further development of arthropathy of the intervertebral joints.

2. During the instability stage, there is a lowering of the vertebral area and a loosening of the joints and further loosening of the yellow ligament chord (ligamentum flavum) and the interspinal ligaments. The result of these pathological anatomical changes is a pathologic increase in the flexibility of the vertebrae.

3. The restabilization stage is characterized by the formation of osteophytes on individual vertebral bodies and by the development of spondylarthrosis (hypertrophy of the intervertebral joints). In this way the spine is restabilized, but at the same time the spinal column is narrowed and the intervertebral openings with their handicapped nerve roots are compressed. Each stage of this process has its own specific clinical symptoms. We are especially concerned here with the problematics of instability of the spine, the cause of which is a degenerative disorder of the spine. The cause of instability of the spine can also be found elsewhere, for example, in trauma, tumour, inflammation or genetic defects. Instability of the spine according to Panjabi is defined as a lowered capability of the spine to react to a physiological stress or strain or to bear a load ${ }^{14}$.

Instability of the spine demands surgical stabilization - a fixation of the affected moveable segment. Various instrumentation methods are used to accomplish this goal, in other words, so-called internal fixation. Fixation methods can be categorized according to the surgical approach. In the case of an approach from the back of the spine, the following methods are used:

1. Transpedicular fixation - screws are put into the vertebral bodies via the pedicle (the joining of the vertebral body with its arch) and individual screws are then fixed by mutual joining of the screws by rods.

2. PLIF (posterior lumbar interbody fusion) so-called interbody fusion with the help of titanium cages after removal of the intervertebral discs.

3. Translaminar facet joint fixation is performed with the help of screws. The intervertebral joints are directly stabilized by inserting the screws through the vertebral arches.

When the spine is approached from the anterior side via the retroperitoneum or through the peritoneum, ALIF (anterior lumbar interbody fusion) can be used - after removal of the intervertebral discs, bone autotransplantation or cages are used to secure fusion between the vertebral bodies. 
Any of these methods can be combined (anterior and posterior approach) for the purpose of securing a greater degree of stability.

There are many possible classifications of instability ${ }^{11,13}$. To put it simply, there are either rotational types of instability moving around, for example, axes X,Y and Z or the type of translation instability which shifts around a single axis ${ }^{11}$. What is more, these rotational or shifting forms may be combined. In the case of more extensive facetectomy, rotational instability appears around axis Y. In the case of laminectomy or hemilaminectomy (the complete or partial removal of the vertebral arch) a rotational/angular form of instability can occur around axis $\mathrm{X}$ or a shift can develop in the area of axis $\mathrm{Z}$. In each case of instability it is necessary to use a particular method of surgical stabilization.

\section{MATERIAL AND METHODS}

The goal of this work was to establish the best stabilization method in individual cases of instability. The study was carried out on human cadaver specimens of lumbar spines (L1-L5). In the case of samples of spines we performed skeletization, which consists of the removal of muscle tissue while leaving in place the discoligamental apparatus. The spines were preserved at a temperature of $-20{ }^{\circ} \mathrm{C}$. After skeletelization all samples are examined by X-ray to determine that there is no malignancy, osteoporosis or noticeable degenerative change, especially spondylosis or spondylolisthesis (Fig. 1). The measuring was carried out on 6 spinal samples, the first three samples served to verify whether or not the equipment was functional, so the results of these tests were not evaluated. Further spinal samples have already been marked by symbols $1-3$.

\section{Basic data about}

- spinal sample No. 1: age 41, male, cause of death - suicide,

- spinal sample No. 2: age 67, male, cause of death - heart attack,

- spinal sample No. 3: age 56, female, cause of death - aneurysm of the brain.

On every spinal sample ventral flexion, dorsal flexion or extension, lateroflexion on both the right and left sides and axial torsion or rotation on the left side as well as axial compression, are measured.

Each of these measurements was carried out

1. on an intact spinal sample

2. a destabilized spinal sample: the degree of destabilization is precisely defined - that is, a right-hand side lateral partial discectomy with removal of anulus fibrosus $(10 \times 14 \mathrm{~mm})$ and of the whole nucleus pulposus and further a right-hand side partial medial facectomy (30 percent) were carried out.

3. Stabilized spinal sample (after an initial destabilization)
- ALIF using cages - cylindrical titanium perforated cages with a thread or coil sized 12-14 × $20 \mathrm{~mm}$, one-sided (from the right side)

- posterior translaminary fixation screws - cortical screws of an average length of $4.5 \mathrm{~mm} \times 40-60 \mathrm{~mm}$ on both sides

- a combination of both methods of fixation. Destabilization of stabilization was carried out in an identical manner in both segments used.

Measurement of biomechanical characteristics of samples of the lower part of the spine was carried out on special equipment especially constructed for this purpose (Fig. 2 and 3). A sample of spine sections L1 to L5 was provided with two fixed aluminum jigs, which with the help of screws are securely attached in both axial and radial directions with L1 and L2, respectively L5 and L4 (Fig. 4). This mechanically secured sample was then placed into the already mentioned measuring device and with the help of additional mechanical parts it was securely joined to those parts of the equipment, which are adapted to individual types of straining of the sample.

Measurement of the parameters of a sample while being strained under pressure in the axis of the spine is carried out with a massive screw (ascension $2 \mathrm{~mm}$ ) through a force meter $(0<\mathrm{F} \leq 1000 \mathrm{~N})$. When the defined turning of the screw (in our case an addition to the axial length of the screw $\Delta \mathrm{l}=0.4 \mathrm{~mm}$ ) a change in the axial strength $\Delta \mathrm{F}$ occurs on the spinal sample, which is expressed as a change in tension measured by the force meter $\Delta \mathrm{U}$ in $\mathrm{mV}$. The force meter is tested before each experiment and therefore changes in tension $\Delta \mathrm{U}$, can be categorized as additional straining strength $\Delta \mathrm{F}$ (Fig. 8).

Measurement of the rotating moment of strength during torsion straining is made possible by the free movement of the axis of rotation around the axis of the spinal specimen, which is brought forth by the pressure of the rotation of a massive screw (the same degree of ascension $-2 \mathrm{~mm}$, but by steps of $\Delta \mathrm{l}=1 \mathrm{~mm}$ ), which affect the shoulder with a constant distance of $\mathrm{d}=80 \mathrm{~mm}$, through the force meter to an extent of $0<\mathrm{F} \leq 200 \mathrm{~N}$. The change in strength $\Delta \mathrm{F}$, respectively the change in the moment of strength $\Delta \mathrm{M}$ is the same as in the preceding example and determined by a change in tension in the torsion straining of the sample, if this sample is strained at the same time by an axial strength of $80 \mathrm{~N}$.

The study of mechanical characteristics of a strained sample, which correspond to flexion, extension and to movement to the left or right is made possible by bending of the upper part of the sample (of the fixed upper aluminum cylinder) with a free axis once again under a load of constant strength $80 \mathrm{~N}$. At a distance of $\mathrm{d}=100 \mathrm{~mm}$ from the axis of rotation of the massive joint, which affects the strength of $\Delta \mathrm{l}=1 \mathrm{~mm}$ through the force meter to an extent of $0<\mathrm{F} \leq 400 \mathrm{~N}$, a change in the strength of $\Delta \mathrm{F}$, respectively the moment of strength $\Delta \mathrm{M}$, which again is equal to the characterized change in tension of force meter $\Delta \mathrm{U}$ in $\mathrm{mV}$. 
With reference to the literature ${ }^{3,4,5,6,7}$ there are biomechanical characteristics of the sample which can be characterized as so-called rigidity. The rigidity, $T_{c}$, of the sample under a pressure load is defined by the following relationship:

$$
\mathrm{T}_{\mathrm{c}}=\frac{\Delta \mathrm{F}}{\Delta \mathrm{l}}
$$

respectively to the dimensions thus indicated:

$$
\left[\mathrm{T}_{\mathrm{c}}\right]=\frac{[\Delta \mathrm{F}]}{[\Delta \mathrm{l}]}=\frac{\mathrm{N}}{\mathrm{mm}}
$$

For movement characterized as flexion, extension, torsion and movement of the right and left sides of the body, we use a unified definition of relational rigidity:

$$
\mathrm{T}_{\mathrm{e}}=\frac{\Delta \mathrm{M}}{\Delta \mathrm{l}}
$$

respectively

$$
\left[\mathrm{T}_{\mathrm{e}}\right]=\frac{[\Delta \mathrm{M}]}{[\Delta \mathrm{l}]}=\frac{\mathrm{Nm}}{\mathrm{mm}}
$$

We measure 2 moveable segments at the same time, that is $\mathrm{L} 2 / 3$ and $\mathrm{L} 3 / 4$. Each measurement was carried out in 7 steps, that is delta $0-6$. The delta value corresponds to the tension measured by the strength measuring device and after recounting according to sample (1)-(4), a resulting rigidity is arrived at. We consider the rigidity of delta 6 to be decisive for all measurements.

During straining and measurement of the rigidity of the sample as a whole it is also necessary to keep an eye on the movement of individual parts of the sample, that is parts L2, L3 and L4. Their behavior is of interest especially with a point of view to the application of various types of destabilizing and fixation methods. This movement is followed with the help of round targets connected to the appropriate vertebra to be observed. The sample, respectively the detectional targets are lit with a lamp, in some cases with a laser, and are watched from two mutually slanted directions by two CCD cameras. An optical signal is brought in through anologodigital units into a computer and evaluated by the fast Fourier transformation method in such a way that the appropriate area frequency of interfering bands (density of bands), respectively the period of the bands and their reverse value determine the size of the shift of the target and the tendency of interferential bands to go in the direction of the shifted target ${ }^{15,16}$. The direction and size of the shift of individual targets, respectively vertebrae L2, L3 and L4, when various destabilizing and fixation methods are introduced, provide information about the size of the deformation of the individual elements of the sample as dependent on the size of the destabilization, respectively in the case of fixation met- hods, the size and direction of the deformation of individual components of the sample, which are characterized by Fourier's pictures as seen on the targets, should be close to the picture detected in the case of an intact spine (Fig. 5).

\section{RESULTS}

Results for all 3 samples are clearly marked in graphs (No. 1-6) for each tested characteristic. Results depicted in the graphics are related to an intact spinal sample (1.00, that means 100 percent) and are therefore normative. Because of the statistically low number of samples, we did not carry out a statistical analysis. Sample No. 3 (Tab. 1) forms the base with which we compare the other two samples.

\section{Sample No. 3:}

Flexion: The rigidity of the intact spinal sample was $0,15 \mathrm{Nm} / \mathrm{mm}$. Destabilization was lowered to 60 percent and, after stabilization using cages, it was lower than in the case of an intact spinal sample (78 percent), but higher than in the case of a destabilized spinal sample. Stabilization by screws, respectively cages and screws, increased rigidity to a level higher than that present in an intact spinal sample (120 percent, respectively 128 percent).

Extension: The rigidity of an intact spinal sample was $0,22 \mathrm{Nm} / \mathrm{mm}$. Destabilization lowered it to 53 percent. In the case of stabilization using cages, the rigidity was lower than in the case of an intact spinal sample (72 percent) and higher than in the case of a destabilized spinal sample. Stabilization by screws meant a rigidity the same as in the case of an intact spinal sample (101 percent) and a combination of cages with screws increased the rigidity to 111 percent.

Lateroflexion on the left side: The rigidity of the intact spinal sample was $0,31 \mathrm{Nm} / \mathrm{mm}$. Destabilization lowered this figure only somewhat to 95 percent. When stabilization was carried out using cages, screws and combinations of both, rigidity was slightly increased (111 percent, 113 percent, 116 percent).

Lateroflexion on the right side: The rigidity of the intact spinal sample was $0,19 \mathrm{Nm} / \mathrm{mm}$. Destabilization lowered this figure to 53 percent. When stabilization was carried out by means of cages as well as screws, rigidity was increased slightly when compared with the intact spine (119 percent and 116 percent) and when both types of fixation were combined, rigidity was increased significantly (164 percent).

Axial torsion: The rigidity of the intact spinal sample was $0,96 \mathrm{Nm} / \mathrm{mm}$. Destabilization was significantly lowered to 57 percent. When stabilized by means of cages, screws and combinations of the two, rigidity was increased when compared to an intact spine (115 percent, 128 percent, 138 percent).

Axial compression: The rigidity of the intact spine was $116,2 \mathrm{~N} / \mathrm{mm}$. Destabilization was slightly reduced to 
71 percent. When stabilized by the use of cages, rigidity was significantly higher (148 percent) than in an intact spine. The screws stabilized less than the cages did (130 percent). A combination of cages and screws led to a very high degree of stabilization (169 percent).

In the case of spinal sample No. 2 a greater degree of rigidity can be observed as opposed to sample No. 3 in the stabilization of flexion, extension and movement on the left side. The reverse is true with regard to torsion, pressure and right-side movement - here there was less rigidity.

Spinal sample No. 1 demonstrated a greater degree of rigidity than sample No. 3 in extension and a lower degree of rigidity in torsion and pressure. In the cases of flexion and movement on both sides, the results were nearly the same.

\section{DISCUSSION}

Surgical stabilization of the spine is a method of treatment of various spinal ailments which is becoming increasingly widely used. In the USA alone, approximately 200000 spinal stabilizations are performed annually ${ }^{3}$. Clear indications are trauma, tumors, infection, a higher degree of spondylolisthesis (grade II-IV) and iatogenic instability. On the other hand, for example, operations on lumbar hernia of the discs or lumbar stenosis are not indications for stabilization. A relative indicator is chronic degenerative illness of the spine, like degenerative spondylolisthesis (grade 1) or segmental instability ${ }^{10}$. What is more, any surgical operation which secures decompression of the nerve structures in the spinal column, at the present time always leads to further destabilization of the spine. A spine which was relatively stable prior to surgery can in this way require stabilization concurrently or at some point afterwards.

The goal of our work was to precisely verify the degree of surgical destabilization of the spine, which requires in any case at least minimal stabilization and further determine a sufficient extent of operational stabilization with minimal invasiveness, which leads to a better clinical condition of the patient. This question has not, up until now, been precisely answered in any publication.

Biomechanical in vitro tests serve to help find answers to the questions thus placed. It has been shown many times, that when certain conditions are fulfilled and if we comprehend that there are certain limits (the exclusion of the influence of the muscles on spinal stabilization), these results are reliably applicable in vivo $^{8,9}$. Tests are carried out on samples of animal spines ${ }^{2,6}$ or on human cadaverous spine samples ${ }^{1,3,4,5,7,11,12}$ where results are always more precise. That is why our study too uses human spine samples.
Panjabi carried out a one-sided lateral partial discectomy and proved, that the removal of nucleus pulposus leads to the greatest destabilization rather than the removal of anulus fibrosus. Destabilization takes place to a similar degree in extension and lateral flexion ${ }^{11}$. Even Glazer arrived at a similar conclusion, when he observed changes in the cases of ventral and lateral partial discectomy. Rigidity was most dramatically reduced in torsion (to 38 percent and 46 percent) and the furthest reduction (to 66 percent and 64 percent) was observed in the case of extension and lateroflexion ${ }^{3,4}$.

Osman carried out a laminectomy and two-sided medial facetectomy and proved a significant lowering of rigidity in extension and rotation ${ }^{12}$. Brodke proved, during a similar spinal operation, a reduction of rigidity, especially in rotation, but for flexion and extension together significantly less rigidity ${ }^{6}$. Deguchi, during a twosided medial facectomy found only an insignificant level of destabilization ${ }^{2}$.

The extent and character of the destabilization carried out by us led to clear destabilization in all observed movements in agreement with the findings of these authors.

In ventral stabilization using cages (ALIF) Tencer proved that there is no difference between various directions of the application of cages nor in the number of applied cages ${ }^{5}$. Important, however, is the construction of interbody substitutions and therefore especially threaded cages are used, which have the most noticeable stabilizing effect. Glazer proved that these cages lead to a noticeable degree of stabilization with regard to compression and are the least effective for extension. Generally their rigidity was higher than that of an intact spine (104 percent - 143 percent $)^{3,4}$. Brodke did not even prove, in any application of cages (PLIF), a doubling of rigidity in comparison with an intact spine ${ }^{6}$.

Our results show a lesser stabilizing effect of the cages used by us, because rigidity in the case of ALIF never reached (except for in compression) that of an intact spine. However, the reason is the particularly greater destabilization of the partial facectomy we performed at the same time.

In the case of posterior transarticular stabilization (translaminar fixation by screws), Deguchi proved a reduction of the extent of movement by 9 percent as opposed to an intact spine ${ }^{2}$. Similarly encouraging results were achieved by Kornblatt as well, who proved a doubling of rigidity in translaminar fixation when compared to an intact spine1.

In our testing we came to similar conclusions, a spine stabilized in this way was always more rigid than an intact spine (with the exception of extension, which remained nearly the same as for an intact spine).

When using a circumferential fixation (ALIF cages and translaminar fixation), rigidity was logically at a maximum degree. 
Extension

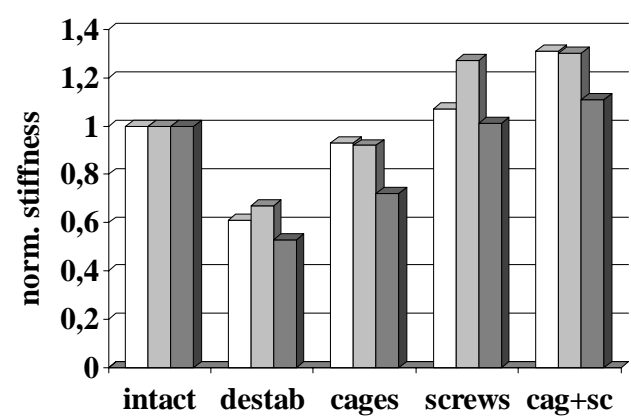

Graph 1.

Left lateral bending

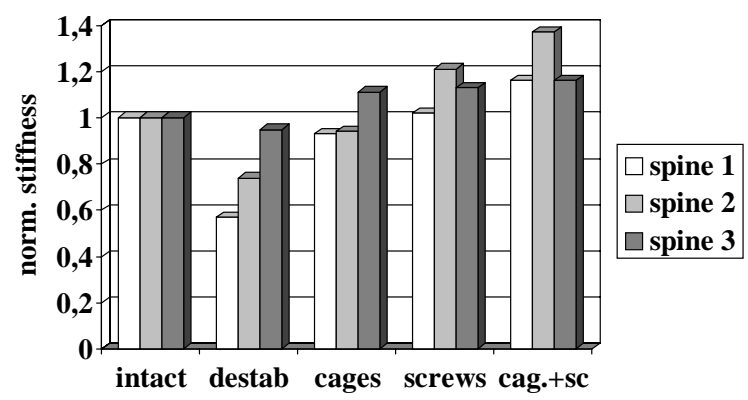

Graph 3.

Axial compression

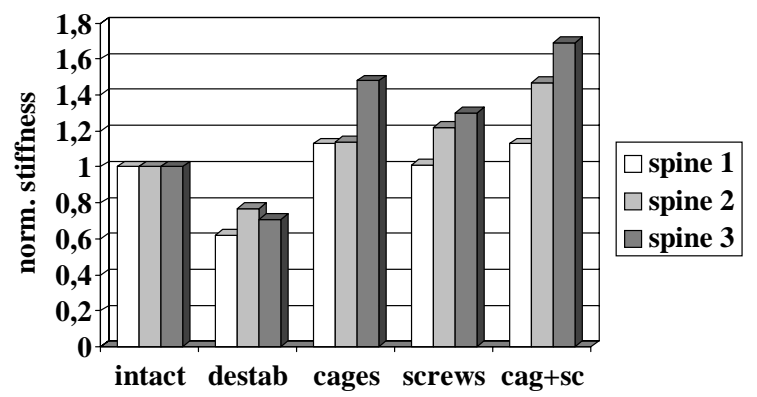

Graph 5.
Flexion



Graph 2.

Right lateral bending

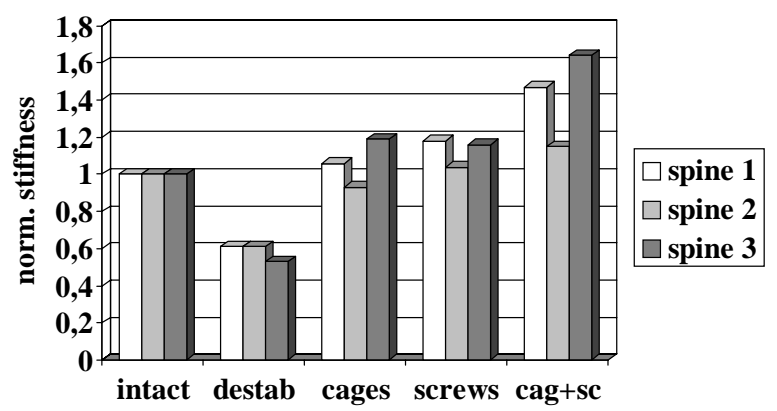

Graph 4.

Torsion

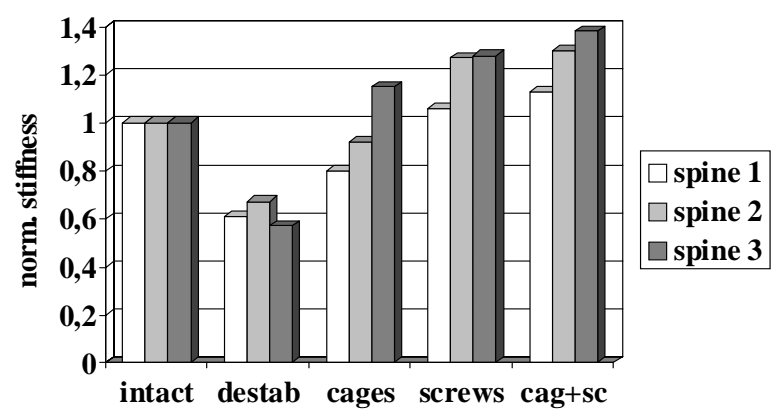

Graph 6. 
Table 1.

\begin{tabular}{|c|c|c|c|c|c|c|}
\hline & & & Exten & sion & & \\
\hline$\frown$ & $\Delta_{\mathrm{m}}$ & instab. & destab. & cages & screws & cag. + sc. \\
\hline$\Xi$ & 0 & 0.322 & 0.245 & 0.257 & 0.354 & 0.339 \\
\hline$=$ & 1 & 0.351 & 0.298 & 0.303 & 0.400 & 0.399 \\
\hline 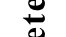 & 2 & 0.442 & 0.328 & 0.345 & 0.458 & 0.472 \\
\hline $\mathbf{\Xi}$ & 3 & 0.504 & 0.351 & 0.379 & 0.517 & 0.531 \\
\hline \& & 4 & 0.572 & 0.382 & 0.429 & 0.578 & 0.600 \\
\hline$\stackrel{0}{0}$ & 5 & 0.631 & 0.411 & 0.482 & 0.665 & 0.683 \\
\hline 5 & 6 & 0.705 & 0.448 & 0.532 & 0.739 & 0.766 \\
\hline $\begin{array}{l}\text { stiff } \\
(\mathrm{Nm}\end{array}$ & $\begin{array}{l}\mathbf{s s} \\
\mathrm{Im})\end{array}$ & 0.22 & 0.11 & 0.16 & 0.22 & 0.25 \\
\hline $\begin{array}{l}\text { norr } \\
\text { stiff }\end{array}$ & & 1.00 & 0.53 & 0.72 & 1.01 & 1.11 \\
\hline
\end{tabular}

Table 3.

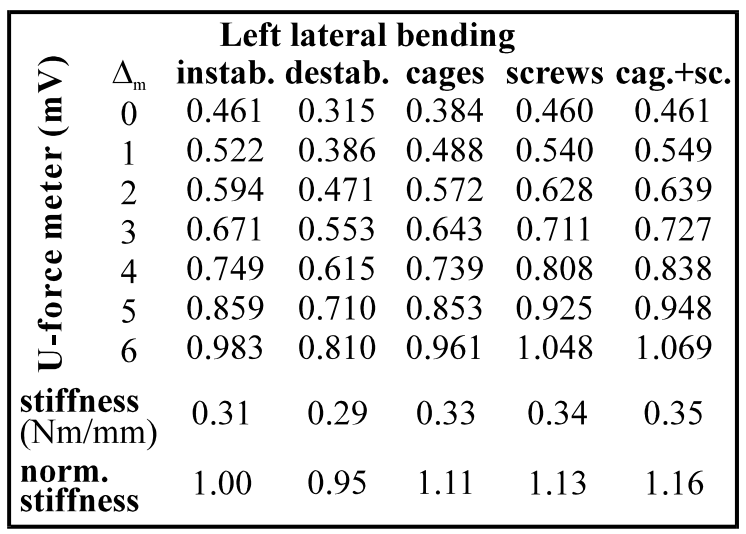

Table 5.

\begin{tabular}{|c|c|c|c|c|c|c|}
\hline \multicolumn{7}{|c|}{ Axial compression } \\
\hline$\Xi$ & 0 & 19.6 & 17.0 & 13.8 & 11.8 & 16.0 \\
\hline 0 & 1 & 25.4 & 21.0 & 20.7 & 21.7 & 23.3 \\
\hline$\stackrel{0}{0}$ & 2 & 28.5 & 22.8 & 28.7 & 25.4 & 32.2 \\
\hline$\Xi$ & 3 & 33.8 & 26.5 & 31.7 & 30.6 & 38.0 \\
\hline 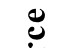 & 4 & 38.1 & 31.2 & 37.3 & 36.5 & 48.0 \\
\hline 0 & 5 & 42.6 & 33.5 & 45.9 & 41.0 & 57.2 \\
\hline 5 & 6 & 47.5 & 36.8 & 55.1 & 48.0 & 63.1 \\
\hline $\begin{array}{l}\text { stiff } \\
(\mathrm{Nm}\end{array}$ & $\begin{array}{l}\text { ess } \\
\mathrm{nm} \text { ) }\end{array}$ & 116.2 & 82.50 & 172.00 & 150.80 & 196.20 \\
\hline nor & & 1.0 & 0.71 & 1.48 & 1.30 & 1.69 \\
\hline
\end{tabular}

Table 2.



Table 4.

\begin{tabular}{|c|c|c|c|c|c|c|}
\hline & & Rig & t laters & l bend & ing & \\
\hline 1 & $\Delta_{\mathrm{m}}$ & instab. & destab. & cages & screws & cag.+sc. \\
\hline$\Xi$ & 0 & 0.365 & 0.349 & 0.412 & 0.446 & 0.458 \\
\hline$=$ & 1 & 0.428 & 0.361 & 0.481 & 0.499 & 0.514 \\
\hline & 2 & 0.462 & 0.405 & 0.532 & 0.575 & 0.590 \\
\hline$=$ & 3 & 0.511 & 0.433 & 0.582 & 0.615 & 0.686 \\
\hline e & 4 & 0.555 & 0.459 & 0.649 & 0.677 & 0.769 \\
\hline 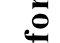 & 5 & 0.627 & 0.489 & 0.725 & 0.753 & 0.881 \\
\hline 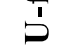 & 6 & 0.693 & 0.523 & 0.803 & 0.827 & 0.997 \\
\hline $\begin{array}{l}\text { stift } \\
\text { (Nm }\end{array}$ & $\begin{array}{l}\text { ess } \\
\mathrm{nm} \text { ) }\end{array}$ & 0.19 & 0.10 & 0.23 & 0.22 & .31 \\
\hline $\begin{array}{l}\text { nor } \\
\text { stif }\end{array}$ & & 1.00 & 0.53 & 1.19 & 1.16 & 1.64 \\
\hline
\end{tabular}

Table 6.

\begin{tabular}{|c|c|c|c|c|c|}
\hline \multicolumn{6}{|c|}{ Torsion } \\
\hline$\Delta_{\mathrm{m}}$ & instab & destab. & cages & screws & cag. + sc. \\
\hline$\Xi$ & 0.67 & 0.16 & 0.55 & 0.41 & 0.58 \\
\hline$=$ & 1.06 & 0.72 & 2.02 & 1.55 & 1.95 \\
\hline 2 & 1.61 & 1.43 & 3.88 & 3.04 & 3.14 \\
\hline$\Xi$ & 2.54 & 2.15 & 5.11 & 5.21 & 5.81 \\
\hline ¿ & 3.81 & 2.86 & 6.34 & 6.15 & 6.90 \\
\hline 0 & 5.61 & 3.58 & 7.70 & 7.90 & 8.50 \\
\hline $\bar{b}$ & 7.88 & 4.29 & 8.85 & 9.65 & 10.50 \\
\hline $\begin{array}{l}\text { stiffness } \\
(\mathrm{Nm} / \mathrm{mm})\end{array}$ & 0.96 & 0.55 & 1.10 & 1.23 & 1.32 \\
\hline $\begin{array}{l}\text { norm. } \\
\text { stiffness }\end{array}$ & 1.00 & 0.57 & 1.15 & 1.28 & 1.38 \\
\hline
\end{tabular}




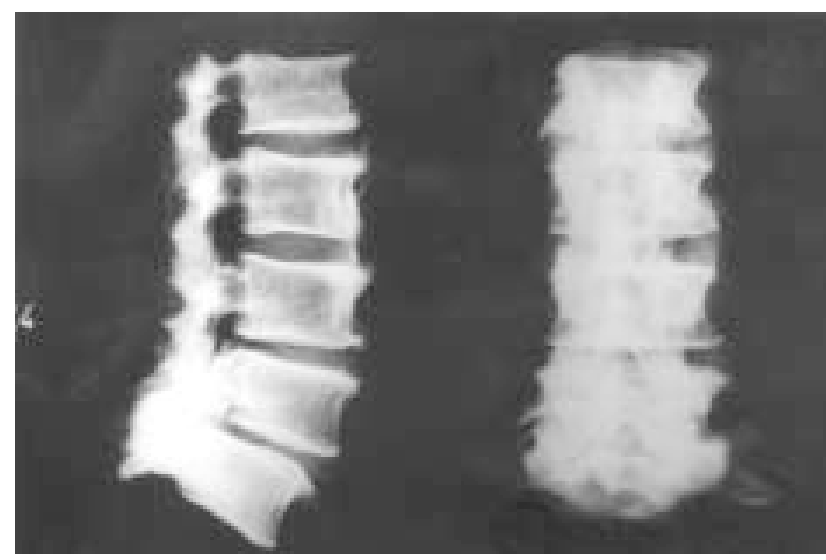

Fig. 1 After skeletization all samples are examined by X ray

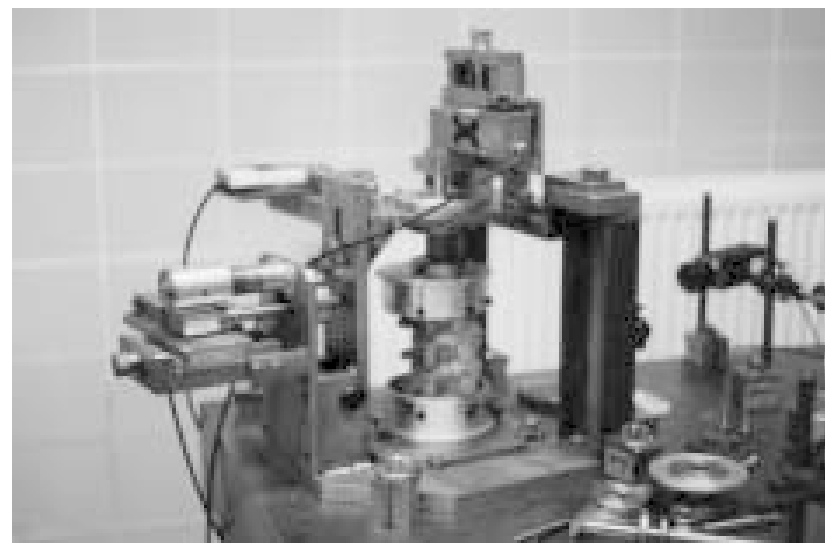

Fig. 2 Testing device for measurment of flexion

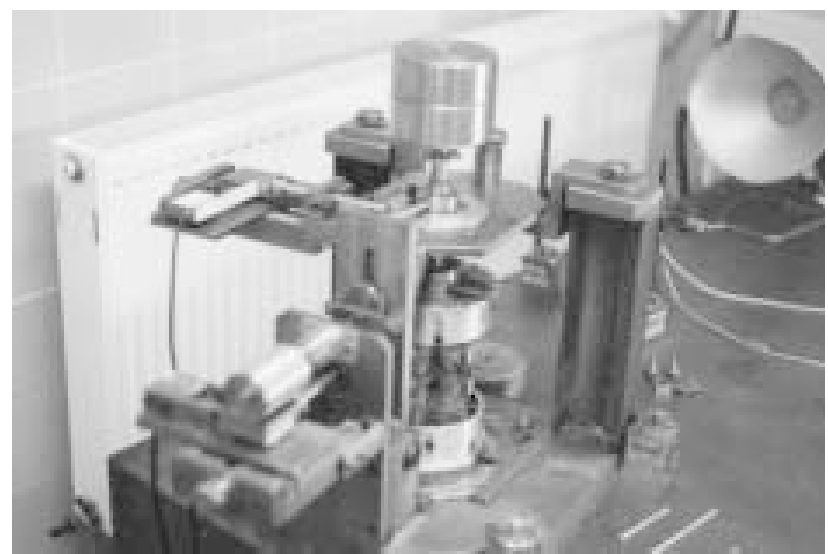

Fig. 3 Testing device for measurment of axial torsion

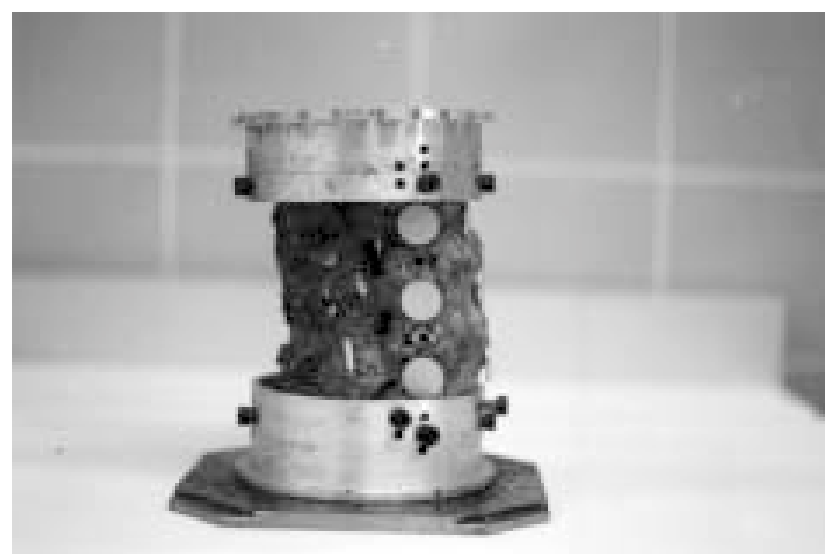

Fig. 4 Bilateral translaminar screw fixation nad anterior interbody. Fusion (Cages) L2/3 and L3/4

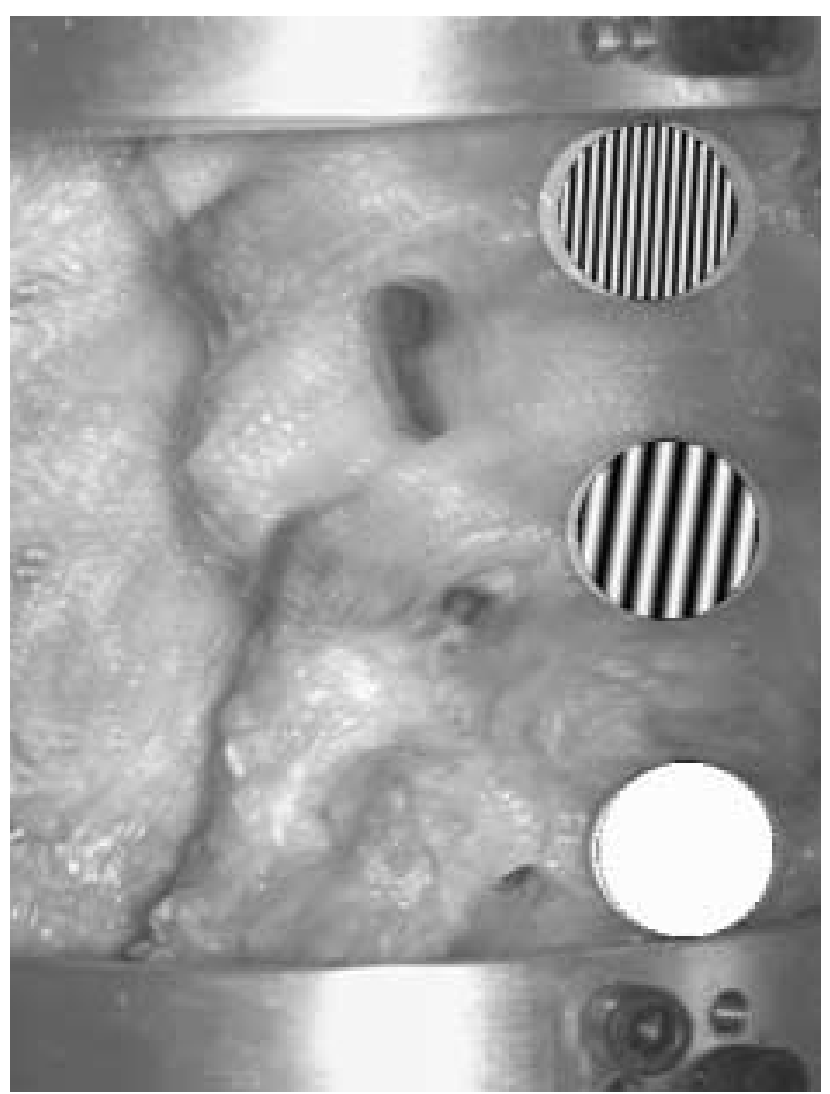

Fig. 5 Furier's torsion transformation

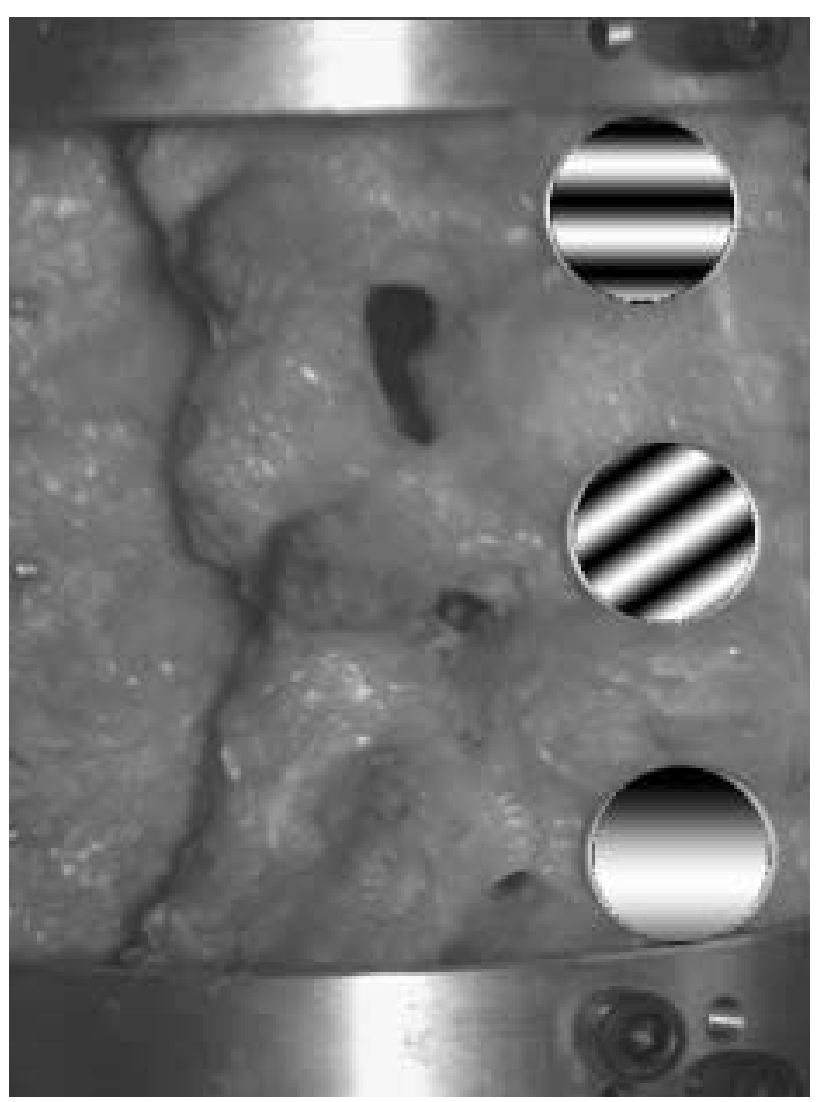

Fig. 6 Furier's rotation transformation 


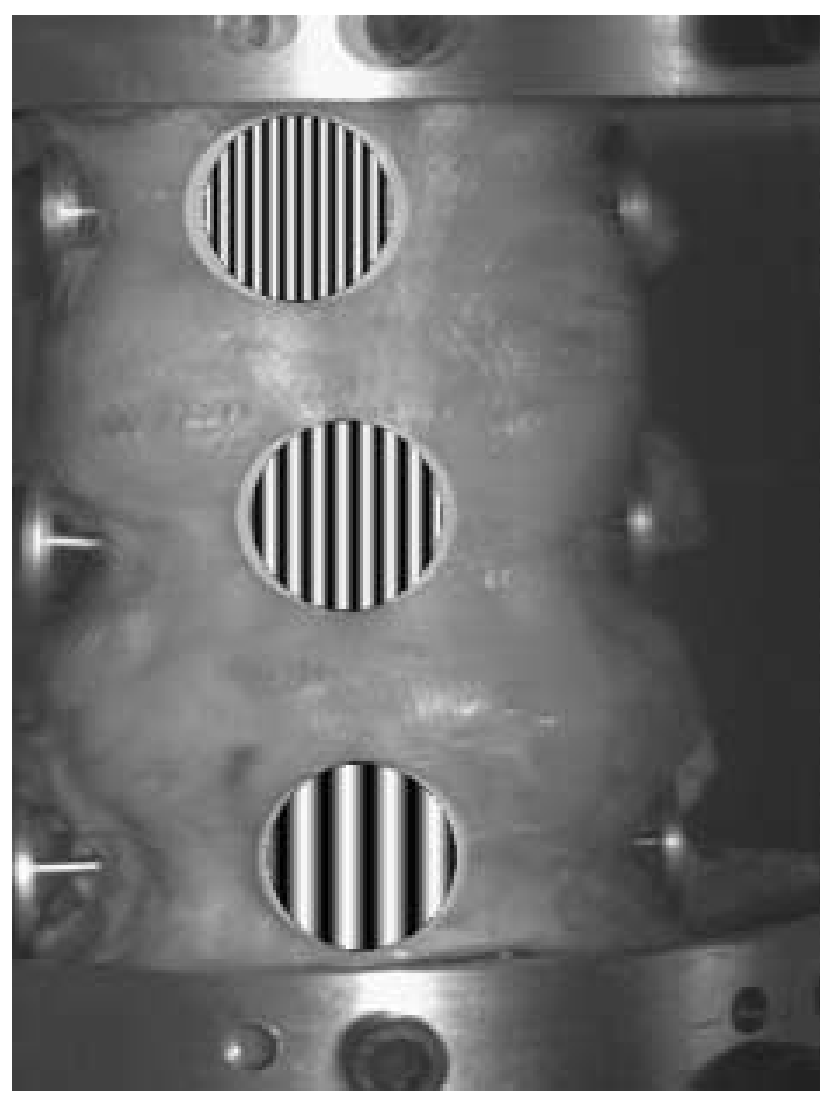

Fig. 7 Furier's axial compression transformation

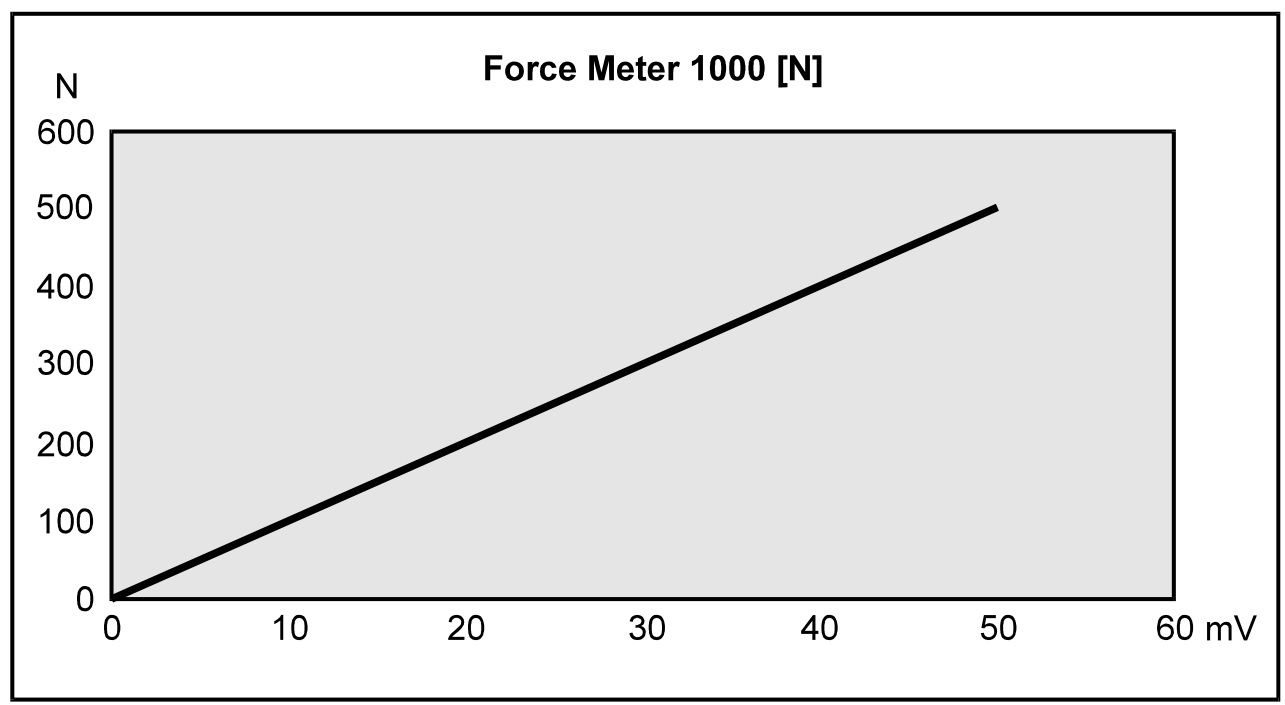

\begin{tabular}{|rr|}
\hline $\mathbf{U}[\mathbf{m V}]$ & $\mathbf{F}[\mathbf{N}]$ \\
0.17 & 1.7 \\
0.22 & 2.2 \\
0.27 & 2.7 \\
0.33 & 3.3 \\
0.37 & 3.7 \\
0.58 & 5.8 \\
0.69 & 6.9 \\
0.90 & 9.0 \\
1.23 & 12.3 \\
1.53 & 15.3 \\
1.84 & 18.4 \\
2.26 & 22.6 \\
5.00 & 50.0 \\
10.00 & 100.0 \\
20.00 & 200.0 \\
50.00 & 500.0 \\
\hline
\end{tabular}

Fig. 8 Calibration force meter graph 


\section{CONCLUSION}

In conclusion it is possible to state that in simulating a common surgical situation, which requires partial discectomy concurrently with partial facetectomy, a considerable destabilization of the spine results. By using minimally invasive procedures of stabilization, that is ALIF with a ventral approach or translaminar fixation with a posterior approach, an inadequate amount of stabilization is achieved.

By using combinations of both methods of stabilization though, the rigidity of the spine is increased to such a level, that it forms good conditions for thorough bone healing without causing pseudoarthrosis and that a good clinical effect is achieved. This work was performed thanks to grant support provided by Palacký University.

\section{ACKNOWLEDGMENTS}

Supported by a grant of the grant agency, UP, grant no 1130 1101. And further we would like to thank our translator Jessica Jayne Maertin for her fast and careful work.

\section{REFERENCES}

1. Kornblatt, M. D., Casey, M. P., Jacobs, R. R. (1986) Internal Fixation in Lumbosacral Spine Fusion: A Biomechanical and Clinical Study. Clin. Orthop. 203, 141-150.

2. Deduchi, M., Chang, B. C., Sato, K., Matsujama, Y., et al. (1998) Biomechanical Evaluation of Translaminar Facet Joint Fixation:
A Comparative study of Poly-L-Lactide Pins, Screws, and Pedicle Fixation. Spine 12, 1307-1313.

3. Glazer, P. A., Colliou, O., Klisch, S. M., et al. (1997) Biomechanical Analysis of Multilevel Fixation Methods in the Lumbar Spine. Spine 2, 171-182.

4. Glazer, P. A., Colliou, O., Lotz, J. C., Bradfort, D. S. (1996) Biomechanical Analysis of Lumbosacral Fixation. Spine 10, 1211-1222.

5. Tencer, A. F., Hampton, D., Eddy, S. (1995) Biomechanical Properties of Threaded Inserts for Lumbar Interbody Spinal Fusion. Spine 22, 2408-2414.

6. Brodke, D. S., Dick, J. C., Kunz, D. N., McCabe, R., et al. (1997) Posterior Lumbar Interbody Fusion: A Biomechanical Comparison, Including a New Threaded Cage. Spine 1, 26-31.

7. Esses, S. I., Doherty, B. J., Crawford M. J., Dreyzin, V. (1996) Kinematic Evaluation of Lumbar Fusion Techniques. Spine 6, 676-684.

8. Adams, M. A. (1995) Spine. Update Mechanical Testing of the Spine. An Appraisal of Methodology, Results, and Conclusions. Spine 19, 2151-2156.

9. Goel, V. K., Wilder, D. G., Pope, M.H., Edwards, W. T. (1995) Controversy Biomechanical Testing of the Spine: Load-Controlled Versus Displacement-Controlled Analysis. Spine 21, 2354-2357.

10. Sonntag, V. K. H., Marciano, F. F., (1995) Is Fusion Indicated for Lumbar Spinal Disorders? Spine 245, 1385-1425.

11. Panjabi, M. M., Krag, M. H., Chung, T. Q. (1984) Effects of Disc Injury on Mechanical Behavior of the Human Spine. Spine 7.

12. Osman, S. G., Nibu, K., Panjabi, M. M., Marsolais, E. B., et al. (1997) Transforaminal and Posterior Decompresions of the Lumbar Spine: A comparative Study of Stability and Intervertebral Foramen Area. Spine 15, 1690-1695.

13. Kirkaldy-Willis, W. H., Farfan, H. F. (1982) Instability of the Lumbar Spine. Clin. Orthop. 165, 110-123.

14. White, A. A., Panjabi, M. M. (1978) Clinical Biomechanics of the Spine. Philadelphia: J. B. Lippincott.

15. Keprt, J., Bartoněk, L. (1999) Measurement of Small Deformations by Laser Speckle Interferometry. Acta UP, Fac. Rer. Nat. $38,115-125$.

16. Jaroslavskij, L., Bajla, I. (1989) Metódy a systémy číslicového spracovania obrazov, Alfa, Bratislava. 